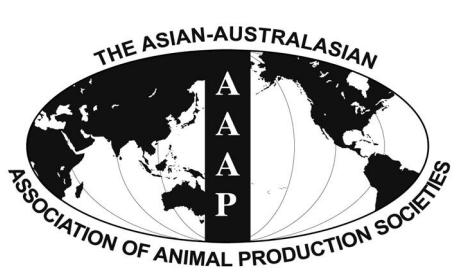

Open Access

Asian Australas. J. Anim. Sci.

Vol. 28, No. 9 : 1303-1308 September 2015

http://dx.doi.org/10.5713/ajas.14.0535

www.ajas.info

pISSN 1011-2367 elSSN 1976-5517

\title{
Study on the Changes in Enzyme and Insulin-like Growth Factor-1 Concentrations in Blood Serum and Growth Characteristics of Velvet Antler during the Antler Growth Period in Sika Deer (Cervus nippon)
}

\author{
Jaehyun Park, Byongtae Jeon, Sungki Kang ${ }^{1}$, Mirae Oh, Myonghwa Kim, Seyoung Jang, \\ Pyojam Park ${ }^{2}$, Sangwoo Kim ${ }^{3}$, and Sangho Moon* \\ Korea Nokyoung Research Center, Division of Food Bio Science, Konkuk University, Chungju 380-701, Korea
}

\begin{abstract}
This study was conducted to investigate changes in blood enzyme parameters and to evaluate the relationship between insulin-like growth factor-1 (IGF-1), antler growth and body weight during the antler growth of sika deer (Cervus nippon). Serum enzyme activity and IGF-1 concentrations were measured in blood samples collected from the jugular and femoral veins at regular intervals during the antler growth period. Blood samples were taken in the morning from fasted stags $(\mathrm{n}=12)$ which were healthy and showed no clinical signs of disease. Alfalfa was available ad libitum and concentrates were given at $1 \%$ of body weight to all stags. The experimental diet was provided at 9 am with water available at all times. There were no significant differences in alkaline phosphatase, aspartate aminotransferase, and alanine aminotransferase during antler growth, but alkaline phosphatase concentrations increased with antler growth progression, and the highest alkaline phosphatase concentration was obtained 55 days after antler casting. Serum IGF-1 concentrations measured from blood samples taken from the jugular vein during antler growth, determined that levels of IGF-1 was associated with body weight and antler growth patterns. Serum IGF-1 concentrations were higher at the antler cutting date than other sampling dates. Antler length increased significantly during antler growth $(\mathrm{p}<0.001)$, and there was a similar trend to between right and left beams. Body weight increased with antler growth but was not significant. Consequently it appeared that serum alkaline phosphatase concentration was related to antler growth and both antler growth and body weight were associated positively with IGF-1 concentrations during antler growth. (Key Words: Antler, Blood enzyme, IGF-1, Sika Deer)
\end{abstract}

\section{INTRODUCTION}

Deer are intermediate feeders which can adapt well to browse and forages (Kay et al., 1980; Hofmann, 1985; 1989). They have small and simple stomachs which are an adaptation to highly digestible materials (concentrate selectors) and for the extended retention of slowly digested, fibrous foods (roughage eaters). Velvet antler is soft growing antler tissue, which is cast off and re-grown every

\footnotetext{
* Corresponding Author: Sangho Moon. Tel: +82-43-8403527, Fax: +82-43-8518216, E-mail: moon0204@kku.ac.kr

${ }^{1}$ Cheilbio Co. Ltd, Ansan 425-100, Korea.

${ }^{2}$ Korea Nokyoung Research Center, Department of Biotechnology, Konkuk University, Chungju 380-701, Korea.

${ }^{3}$ National Institute of Animal Science, RDA, Unbong, Namwon, Cheonbuk, 590-832, Korea.

Submitted Jul. 18, 2014; Revised Aug. 18, 2014; Accepted Aug. 23, 2014
}

year. Velvet antlers are made of cartilage and differ from the horns found on bovids which do not fall off ever year (Haigh and Hudson, 1993). Blood carries the necessary nutrients and cell metabolism material into antler tissues during the antler growth. It is hypothesized that blood biochemical constituents have an influence on velvet antler growth (Muir et al., 1988). Antler blood collected when antler is cut, is called dehorned blood, and has been used to promote health in Asia for thousands of years, but studies have shown that there is no difference between dehorned blood and circulatory blood (Choi et al., 1998). Some researchers have already reported haematology values for various domestic and wild animals (Reid and Towers, 1985; Karesh et al., 1986; Maeda et al., 1990; Chapple et al., 1991). However these results are difficult to apply in Korea where farming conditions differ from those of other countries, and haematology values are influenced by age, 
sex, climate, nutrition, disease and sampling methods (Karesh et al., 1986; Catley et al., 1990; Maeda et al., 1990; Chapple et al., 1991). Previous research related to antler production has mainly investigated the relationship between changes in body weight, pedicle development and insulinlike growth factor-1 (IGF-1) by years or seasons. In addition, blood sampling has usually just been carried out at antler casting and regulation of the changes in blood constituents, antler growth and IGF-1 in deer have been little investigated. Therefore, this study was conducted to provide basic data on changes of blood enzymes and IGF-1 levels during antler growth in sika deer by comparing samples from the jugular and femoral vein (which is positioned in the body region farthest from the jugular).

\section{MATERIALS AND METHODS}

\section{Animals and their management}

This study was conducted at the HANA deer research institute $\left(36.9^{\circ} \mathrm{N}\right)$, Chungju, Chungcheongbuk-do, Korea, from March to October in 2008. Twelve sika deer (Cervus nippon) stags were used in this study. Mean body weight was $77.7 \pm 5.2 \mathrm{~kg}$ at the beginning of the study. All deer were individually housed in outdoor pens $(5 \times 4 \mathrm{~m})$ during the experimental period. Alfalfa was available ad libitum and concentrates were given at $1 \%$ of body weight to all deer. Experimental diets were provided at 9 am (but delayed after blood collection on sampling day) with water available at all times. The chemical composition of the experiment diets are presented in Table 1.

\section{Blood sampling}

Blood samples were obtained from the jugular vein and femoral vein and were taken at 18-day intervals from the casting date to the cutting date (55 days later). Samples were taken at the same time before feeding (10:00 to 12:00 hours). The blood sampling occurred after an intramuscular injection of muscular relaxant (suxamethonium chloride, $0.1 \mathrm{~mL} / 20 \mathrm{~kg}$ body weight) had been administrated to each animal by a veterinarian. The blood samples $(15 \mathrm{~mL})$ were immediately transferred to tubes and then centrifuged at $3,000 \mathrm{rpm}$ for $15 \mathrm{~min}$ to separate serum. Separated serum was removed and stored at $-40^{\circ} \mathrm{C}$ until required for analysis.

\section{Measurement}

Blood samples were prepared for analysis of blood enzymes and IGF-1. Antler length and body weight were measured at the same time on each blood sampling day. The inside antler length (main beam) was measured from the burr to the outer tip. Burr and pedicle circumference were measured at the cutting day (55 days after casting). All measurements were carried out using a tapeline.

\section{Chemical analysis}

Blood constituents were analysed using an auto blood analyser (EPX. Abbott Spectrum model: Abbott Laboratories, Lake Forest, IL, USA). Blood enzyme activity values of alkaline phosphatase (AP), aspartate aminotransferase (AST), alanine aminotransferase (ALT) were determined. Serum IGF-1 concentration was measured by radioimmunoassay after acid ethanol extraction using the method of Gluckman and Butler (1983), as validated for deer by Suttie et al. (1985). Feed samples were analysed for crude protein, ether extract, crude fiber, and ash including calcium $(\mathrm{Ca})$ and phosphorus $(\mathrm{P})$ according to the methods of the Association of Official Analytical Chemists (AOAC, 1990). Neutral detergent fiber and acid detergent fiber was analyzed by the procedures of Van Soest et al. (1991).

\section{Statistical analysis}

Data were expressed as means and standard errors and were statistically analysed with turkey's multiple range tests using the SAS package (1998) general linear models procedure.

\section{RESULTS AND DISCUSSION}

\section{Changes of enzyme values}

After antler casting, changes in serum enzyme levels in the jugular and femoral veins of sika deer are shown in Figure 1. There was no significant difference in the AST, ALT, and AP in serum by sampling date and between the jugular and femoral vein. The AST levels in serum from the jugular vein were highest 18 days after casting (86.25 IU/L), and slightly decreased to 54.25 IU/L 36 days after casting and remained at this level the rest of the antler growth period. On the other hand, AST levels ranged from 50.00 $\mathrm{IU} / \mathrm{L}$ to $57.25 \mathrm{IU} / \mathrm{L}$ in femoral vein over the same period.

At antler casting, ALT levels in the jugular vein were $34.75 \mathrm{IU} / \mathrm{L}$ which decreased to $28.50 \mathrm{IU} / \mathrm{L} 18$ days after casting and remained at this level until 55 days after casting. Similar ALT levels were found in blood samples from the

Table 1. The chemical composition of experimental diets

\begin{tabular}{|c|c|c|c|c|c|c|c|c|c|}
\hline Item & DM & $\mathrm{CP}$ & EE & $\mathrm{CF}$ & $\mathrm{ADF}$ & NDF & Ash & $\mathrm{Ca}$ & $\mathrm{P}$ \\
\hline & & - & -- & - & $\%$ in $\mathrm{D}$ & 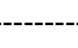 & & & \\
\hline Alfalfa bale & 88.0 & 16.4 & 1.8 & 34.3 & 41.2 & 56.3 & 8.0 & 1.3 & 0.2 \\
\hline Concentrates & 89.4 & 16.0 & 4.0 & 18.6 & 11.7 & 36.7 & 2.3 & 0.7 & 0.4 \\
\hline
\end{tabular}

DM, dry matter; CP, crude protein; EE, ether extract; CF, crude fiber; ADF, acid detergent fiber; NDF, neutral detergent fiber. 

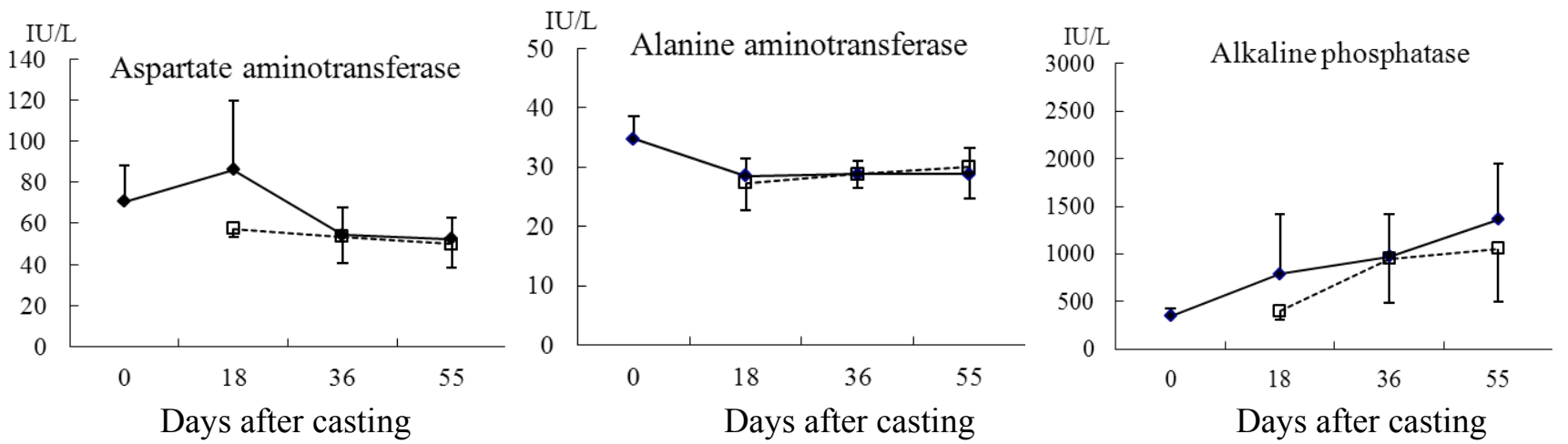

$$
- \text {-Jugular } \quad-\square-\text { Femoral }
$$

Figure 1. Changes in serum enzyme levels in jugular and femoral veins of sika deer. Values are means, and standard errors are represented by vertical bars.

femoral vein. In previous studies, AST levels were increased by the impact of stress when deer were captured by physical means (Spraker, 1993; Marco and Lavin, 1999). The serum AST levels were 63.2 IU/L in red deer captured by chemical means and that doubled in animal captured by physical means, and ALT level were $31.2 \mathrm{IU} / \mathrm{L}$ following chemical immobilization and $55.1 \mathrm{IU} / \mathrm{L}$ in deer captured by physical means (Marco and Lavin, 1999). The serum AST levels decreased slightly from 18 to 36 days after casting and were stable at the cutting date, which suggests that animals may have been accustomed to handling.

AP level increased in both veins during antler growth. AP levels were $348.0 \mathrm{IU} / \mathrm{L}$ at casting and increased dramatically to $1,361.3 \mathrm{IU} / \mathrm{L}$ by the cutting date in the jugular vein samples although this increase was not significantly different. A similar non-significant increase in AP levels was observed in the femoral vein samples throughout antler growth with AP levels not different between the two veins. This result is in contrast to previous research, which showed that during rapid antler growth, plasma concentrations of AP were significantly higher in local antler veins than the other veins (Bubenik et al., 1987). Higher AP levels associated with velvet antler growth have also been reported in fallow deer (Eiben et al., 1984) and white-tailed deer (Karen et al., 1988). The current study had a similar trend. On the other hand, Chao et al. (1985) and Sakkinen et al. (1999) reported that AP concentrations in plasma were higher with advancing pregnancy, and AP concentrations were higher in rapidly growing fawns than in adult and juvenile white-tail deer (Karen et al., 1988). So, AP activity may be associated with skeletal development and calcium absorption.

The antler bone and cartilage may be unique, but their composition is not significantly different from that of other skeletal elements in the body. When in velvet, the cartilage of an antler possesses the usual array of AP found in cartilage elsewhere in the animal (Goss, 1983). In this study it was also shown that AP concentrations increased with progressive antler growth. Further work is necessary to investigate the correlation between AP levels and antler growth.

\section{Growth pattern of velvet antler}

The growth changes in the velvet antler length from previous antler casting until antler cutting in sika deer are shown in Figure 2. The antler length of the main beam was
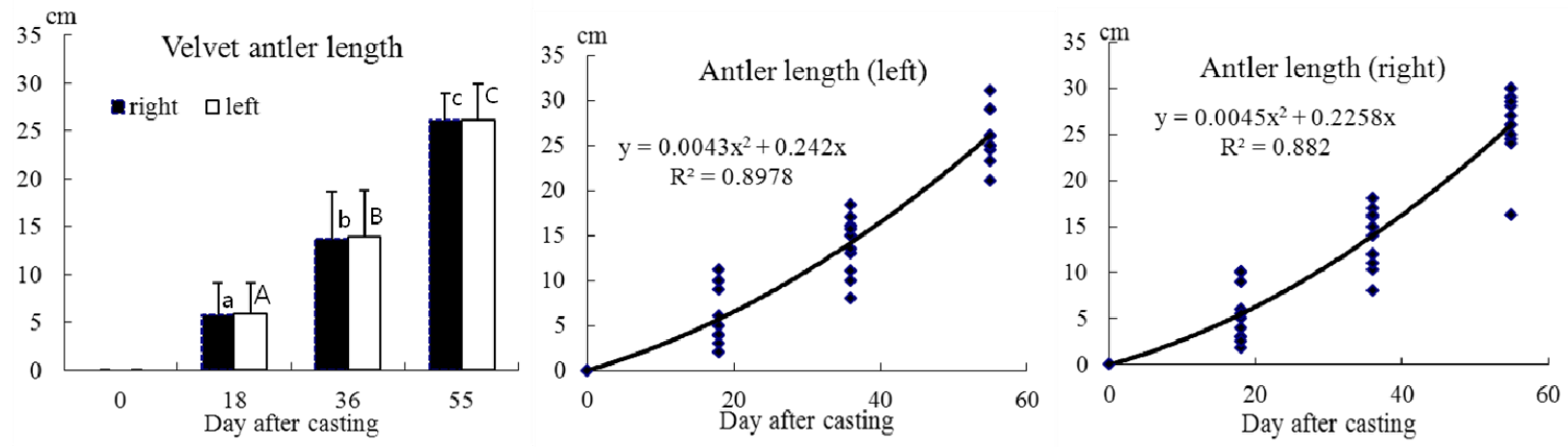

Figure 2. Growth changes in the velvet antler length from casting until cutting date. Values are means, and standard errors are represented by vertical bars. Lines through individual length measurement are means of quadratic regression equations. ${ }^{\mathrm{a}, \mathrm{b}, \mathrm{c}}$ and $^{\mathrm{A}, \mathrm{B}, \mathrm{C}}$ Means with different superscripts in the velvet antler length are significantly different. 
measured on the inside of the antler from the burr to the outer tip by tapeline. At 18 days after casting the main beam length was $5.8 \mathrm{~cm}$ and was growing at a rate of $0.32 \mathrm{~cm} / \mathrm{d}$. Between 18 and 36 days, the antler grew $13.6 \mathrm{~cm}$ at a rate of $0.43 \mathrm{~cm} / \mathrm{d}$, and growth rate increased to $0.7 \mathrm{~cm} / \mathrm{d}$ from 36 to 55 days after casting. The velvet antlers grew $26.0 \mathrm{~cm}$ during the study at an average rate of $0.47 \mathrm{~cm} / \mathrm{d}$ in the right beam, and $25.4 \mathrm{~cm}$ at an average rate of $0.46 \mathrm{~cm} / \mathrm{d}$ in the left beam. There was a significant difference in progressive velvet length $(\mathrm{p}<0.001)$, but no significant difference between left and right beams. It was noted that $22 \%$ of the total velvet antler growth occurred in the first 18 days after casting, $31 \%$ between 18 and 36 days and $47 \%$ of the total antler growth between days 36 and 55. There was correlation between velvet antler length and growth day, and the quadratic regression equations (a) for the growth of the right beam and (b) for the growth of the left beam are given below;

$$
\begin{aligned}
& Y=0.0043 X^{2}+0.242 X(r=0.89) \\
& Y=0.0045 X^{2}+0.2258 X(r=0.88)
\end{aligned}
$$

Where $\mathrm{Y}=$ velvet antler length and $\mathrm{X}=$ day.

Since elongation of antlers is not linear, daily increments during the steepest inflection of the growth curve are almost double the overall means. The elongation of an antler described a typical S-shaped growth curve. Growth starts slowly in the spring, accelerates exponentially during the summer, and slackens off as fall approaches (Goss, 1983). For instance, antlers of Elk (Cervus Canadensis) reach lengths of $129.5 \mathrm{~cm}$, with a maximum growth rate of 1 to $2 \mathrm{~cm} / \mathrm{d}$ (Goss, 1983), and Price and Allen (2004) also indicated that during the period of rapid growth, the antlers of large species of deer (wapiti or moose) will elongate by more than $2 \mathrm{~cm}$ per day. So, in this study the maximal antler growth rate during the 36 to 55 day period in sika deer was $35 \%$ to $70 \%$ lower than other deer species. A more extensive study is needed to fully correlate growth rate of antler, with sexual cycle, age, and tine length until the rut without cutting the antler. The relationship between length and weight of velvet antler against burr circumference and pedicle circumference are shown in Figure 3, and details of the regression parameters are presented in Table 2.

A regression model showed no differences between length of velvet antler and pedicle circumference, weight of velvet antler and pedicle circumference, and length of velvet antler and burr circumference. However, there was a significant difference between weight of velvet antler and
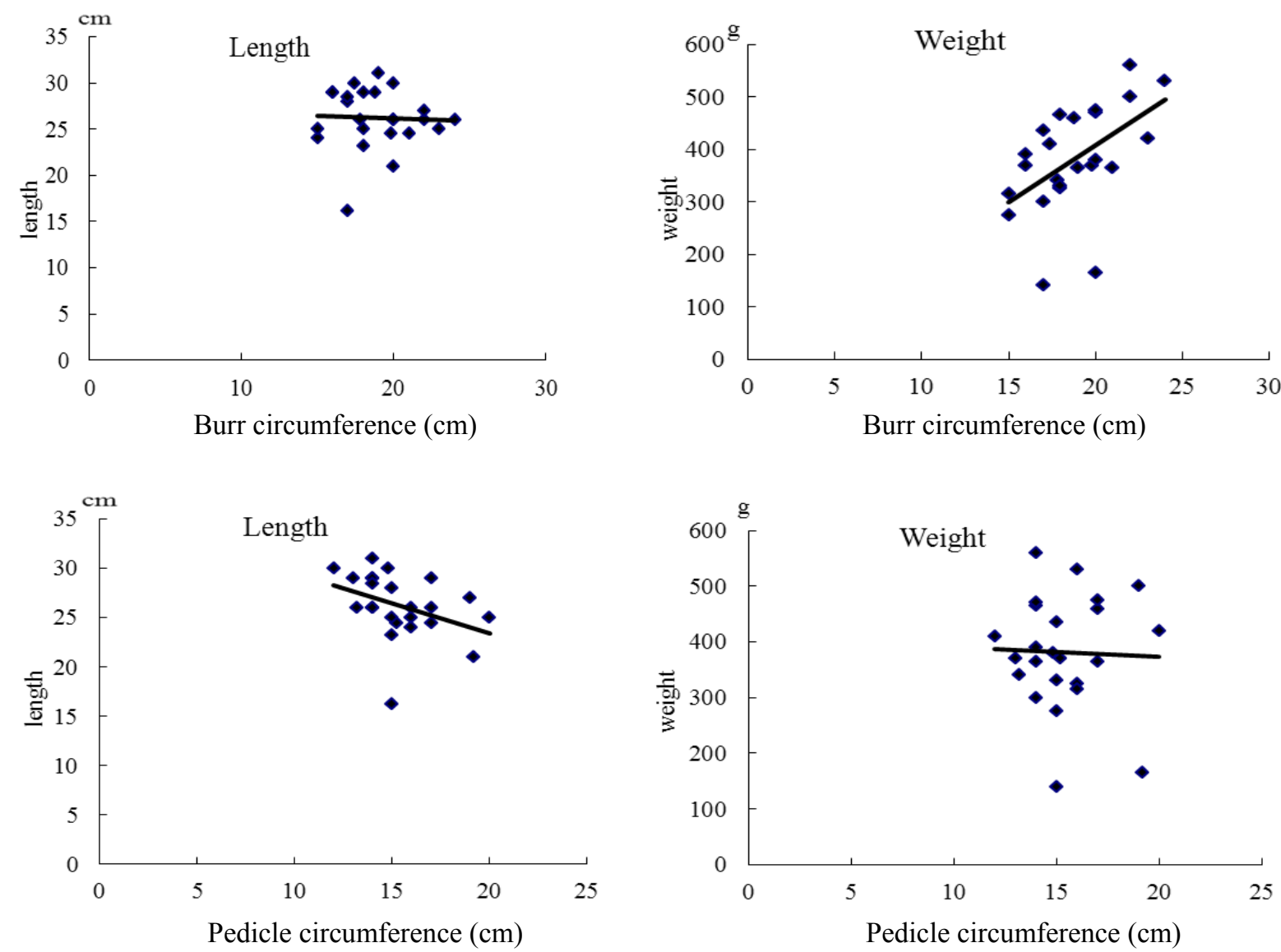

Figure 3. Relationship between length and weight of velvet antler against burr circumference and pedicle circumference. 
Table 2. Results of linear regression of velvet weight, and length versus burr and pedicle circumference

\begin{tabular}{lcccc}
\hline Item & $F$ & $P$ & $R^{2}$ & $\begin{array}{c}\text { Linear regression } \\
\text { equation }\end{array}$ \\
\hline Length/pedicle & 3.64 & 0.069 & 0.14 & $\mathrm{Y}=-0.6125 \mathrm{X}+35.631$ \\
Weight/pedicle & 0.02 & 0.877 & 0.001 & $\mathrm{Y}=-1.6982 \mathrm{X}+407.6$ \\
Length/burr & 0.03 & 0.860 & 0.001 & $\mathrm{Y}=-0.0511 \mathrm{X}+27.166$ \\
Weight/burr & 8.14 & 0.009 & 0.27 & $\mathrm{Y}=-1.6982 \mathrm{X}+407.6$ \\
\hline
\end{tabular}

burr circumference $(\mathrm{p}<0.001)$. Currently, the Korean deer farming industry is interested in production capability per velvet antler. In general, velvet antler production shows a positive relationship between body weight and hard antler weight (Muir and Sykes, 1988), and antler growth is closely related to the individual physiological capability and is thus especially sensitive to changes in nutrient availability (Suttie and Kay, 1982). On the other hand, other studies have shown that antler growth seems to be related more to heritability and endocrine factors than to body condition and access to feed (Haigh and Hudson, 1993). However, further research is needed using larger number of the same aged animals to separate the genetic and production parameters associated with antler production. This work is necessary to improve velvet antler production and adjust the economic population of deer and will give information to farmers when they are buying deer because antler size is an important determinant of breeding success in male deer.

\section{Insulin-like growth factor-1 and growth pattern}

The relationship between body weight, velvet antler length and IGF-1 levels from casting to the cutting date is shown in Figure 4. Serum IGF-1 concentrations ranged from 528.3 to $644.8 \mathrm{ng} / \mathrm{mL}$ during the antler growth period. Serum IGF-1 concentrations decreased to $528.3 \mathrm{ng} / \mathrm{mL}$ at 18 days, recovered to $579.0 \mathrm{ng} / \mathrm{mL}$ at 36 days, and further increased to $644.8 \mathrm{ng} / \mathrm{mL}$ at 55 days after casting. However,

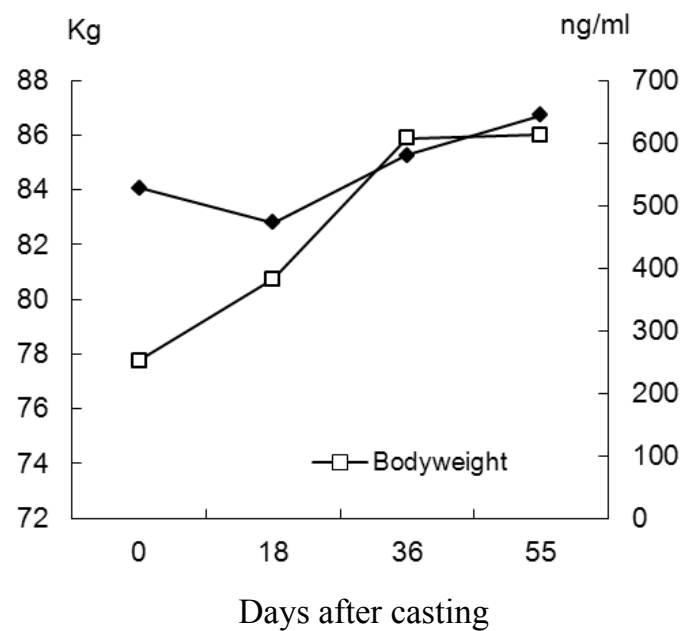

there were no significant differences between the values. Mean body weight increased from $76.9 \mathrm{~kg}$ at the start to $87.0 \mathrm{~kg}$ at the end of experiment. Most $(60 \%)$ of total body weight change occurred from 18 to 36 days after casting, which was mirrored by the change in IGF-1 concentrations. Overall during the study, both antler size and body weight were positively associated with IGF-1 concentrations. Other studies have shown that IGF-1 concentrations vary by species and age. In red deer in New Zealand, plasma IGF-1 concentrations were $2,360 \mathrm{ng} / \mathrm{mL}$ in December (at the start of antler growth) and 2,462 $\mathrm{ng} / \mathrm{mL}$ in February (at the end of antler growth), and dropped sharply to $858 \mathrm{ng} / \mathrm{mL}$ in April (Suttie et al., 1992). In white-tailed deer, serum IGF-1 concentrations ranged from 5.81 to $224.9 \mathrm{ng} / \mathrm{mL}$ during the breeding season (overall mean IGF-1 concentration of 63.6 $\mathrm{ng} / \mathrm{mL}$ ), and IGF-1 concentrations were greatest in animals between 2.5 and 5.5 years of age, with serum IGF-1 concentrations in 3.5 and 4.5 year old deer greater than in 1.5 year old animals (Stephen et al., 2001). The association between high plasma IGF-1 concentration and antler and body growth reported in the current study also agrees with other published studies (Suttie et al., 1985;1991). The data clearly indicate that IGF-1 is a growth factor associated velvet antler growth and body weight.

\section{CONCLUSION}

Both antler growth and body weight were positively associated with IGF-1 concentrations, although other blood enzyme constituents showed no significant changes during the study. In spite of environmental differences and differences in physiological status between individuals, deer can maintain body homeostasis and IGF-1 may be an important factor associated with growing velvet antler and increasing body weight during antler growth. Further research using larger number of the same aged animals is

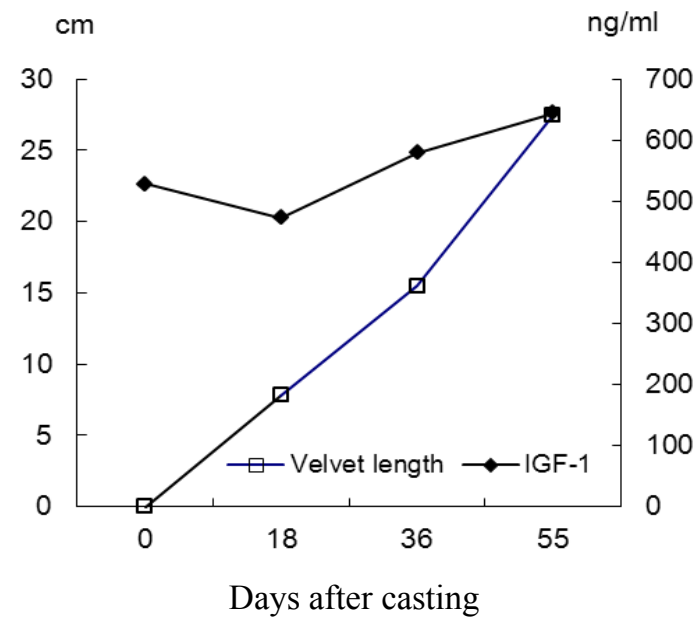

Figure 4. Relationship between changes in body weight, velvet length and insulin-like growth factor-1 (IGF-1) concentrations from casting to cutting date. 
required to separate the genetic and production parameters associated with antler production.

\section{ACKNOWLEDGMENTS}

This work was carried out with the support of the "Cooperative Research Program for Agriculture Science \& Technology Development (Project No. PJ009430)" Rural Development Administration, Republic of Korea.

\section{REFERENCES}

AOAC. 1990. Official Methods of Analysis. 15th edn. Association of official analytical chemists, Washington, DC, USA.

Bubenik, G. A., D. Schams, and G. Voenen. 1987. The effect of artificial photoperiodicity and antiandrogen treatment on the antler growth and plasma levels of LH, FSH, testosterone, prolactin and alkaline phosphatase in the male white-tailed deer. Comp. Biochem. Physiol. Physiol. 87A:551-559.

Catley, A., R. A. Kock, M. G. Hart, and C. M. Hawkey. 1990. Haematology of clinically normal and sick captive reindeer (Rangifer tarandus). Vet. Rec.126:239-241.

Chao, C. C., R. D. Brown, and L. J. Deftos. 1985. Metabolism of calcium and phosphorus during pregnancy and lactation in white-tailed deer. Acta Endocrinol. 109:269-275.

Chapple, R. S., A. W. English, R. C. Mulley, and E. E. Lepherd. 1991. Haematology and serum biochemistry of captive unsedated chital deer (Axis axis) in Australia. J. Wildl Disease. 27:396-406.

Choi, S. H., H. S. Kang, S. H. Choi, and S. K. Cho. 1998. Biological contents of velvet antler and femoral venous blood in farmed Elk (cervus Canadensis). Korean J. Vet. Clin. Med. 15: 251-254.

Eiben, B., S. Scharla, K. Fisher, and H. Schmidt-Gayk. 1984. Seasonal variations of serum 1,25-dihydroxyvitamin D3 and alkaline phosphatase in relation to the antler formation in the fallow deer (Dama dama L.). Acta Endocrinol. 107:141-144.

Gluckman, P. D. and J. H. Butler. 1983. Parturition-related changes in insulin-like growth factors-I and -II in the perinatal lamb. J. Endocrinol. 99:223-232.

Goss, R. J. 1983. Deer Antlers: Regeneration, Function and Evolution. Academics press, New York, NY. pp. 133-171.

Haigh, J. C. and R. J. Hudson. 1993. Farming Wapiti and Red Deer. Mosby-Year Book. Inc. St. Louise, MO, USA. pp. 149-153.

Hofmann, R. R. 1985. Digestive physiology the deer. Their morphophysiological specialization and adaptation. In; Biology of Deer Production. The Royal Society of NZ Bulletin. 22:393-407.

Hofmann, R. R. 1989. Evolutionary steps of ecophysiological adaptation and diversification of ruminants: a comparative view of their digestive system. Oecologia 78:443-457.

Karen, L.V., D. B. Robert, and M. G. Caren. 1988. Circulating levels of 1,25-dihydrozyvitamin D, alkaline phosphatase, hydroxyproline, and osteocalcin associated with antler growth in white-tailed deer. Acta Endocrinol. 118:407-414.

Karesh, W. B., D. L. Janssen, and J. E. Oosterhuis. 1986. Neonatal hematology of selected species of cervidae and bovidae. J. Zoo
Anim. Med. 17:138-146.

Kay, R. N. B., W. V. Engelhardt, and R. G. White. 1980. The digestive physiology of wild ruminants. In: Digestive Physiology and Metabolism in Ruminants (Eds. Y. Ruckebnsch and P. Thivend). pp. 793-761.

Maeda, Y., Y. Yamanaka, A. Sasaki, M. Suzuki, and N. Ohtaishi. 1990. Haematology in sika deer. Jpn. J. Vet. Sci. 52:35-41.

Marco, I. and S. Lavin. 1999. Effect of the method of capture on the haematology and blood chemistry of red deer (Cervus elaphus). Res. Vet. Sci. 66:81-84.

Muir, P. D. and A. R. Sykes. 1988. Effect of winter nutrition on antler development in red deer (Cervus elaphus): A field study. NZ J. Agric. Res. 31:145-150.

Muir, P. D., A. R. Skyes, and G. K. Barrell. 1988. Changes in blood content and histology during growth of antlers in red deer (Cervus elaphus) and their relationship to plasma testosterone levels. J. Anat. 158:31-42.

Price, J. and S. Allen. 2004. Exploring the mechanisms regulating regeneration of deer antlers. Phil. Trans. R. Soc. Lond. B. 359: 809-822.

Reid, T. C. and N. R. Towers. 1985. Blood parameters of normal farmed deer. In: Biology of Deer Production (Eds. P. F. Fennessy and K. R. Drew). Royal Soc. NZ Bull. 22:72-76.

Sakkinen, H., J. Timisjarvi, E. Eloranta, U. Heiskari, M. Nieminen, and M. Puukka. 1999. Nutritional-induced changes in blood chemical parameters of pregnant reindeer hinds (Rangifer tarandus tarandus). Small Rumin. Res. 32:211-221.

SAS Institute Inc. 1988. SAS User's Guide, ver 6.03. Cary, NC, USA.

Spraker, T. R. 1993. Stress and capture myopathy in artiodactylids. In: Zoo and Wild Animal Medicine: Current Therapy, 3rd ed. (Ed. M. E. Fowler). W.B. Saunders Co., Philadelphia, PA, USA. $481-488$.

Stephen, S. D., L. J. Spicer, R. E. Masters, and R. L. Lochmiller, 2001. Concentrations of insulin-like growth factor-I in adult male white-tailed deer (Odocoileus virginianus): associations with serum testosterone, morphometrics and age during and after the breeding season. Comp. Biochem. Physiol. Part A: Mol. Integr. Physiol. 129:887-895.

Suttie, J. M. and R. N. B. Kay. 1982. The influence of nutrition and photoperiod on the growth of antlers of young red deer. In; Antler Development in Cervidae. Texas A \& M Univ. Press, College Station, TX, USA. 61-71.

Suttie, J. M., P. D. Gluckman, J. M. Butler, P. F. Fennessy, T. D. Corson, and F. J. Lass. 1985. Insulin-like growth factor 1 : antler stimualating hormone? Endocrinology 116:846-848.

Suttie, J. M., R. G. White, B. H. Breier, and P. D. Gluckman. 1991. Photoperiod associated changers in insulin like growth factor1 in reindeer. Endocrinology 129:679-682.

Suttie, J. M., B. H. Breier, P. D. Gluckman, R. P. Littlehohn, and J. R. Wwbster. 1992. Effects of Melatonin implants on insulinlike growth factor 1 in male red deer (Cervus elaphus). Gen. Comp. Endocrinol. 87:111-119.

Van Soest, P. J., J. B. Robertson, and B. A. Lewis. 1991. Methods of dietary fiber, neutral detergent fiber, and nonstarch polysaccharides in relation to animal nutrition. J. Dairy Sci. 74:3583-3597. 